\title{
Epidemiological profile of Dupuytren's disease in Taiwan (Ethnic Chinese): a nationwide population-based study
}

\author{
Chin-Choon Yeh ${ }^{1}$, Kuo-Feng Huang ${ }^{1}$, Chung-Han Ho ${ }^{2,3}$, Kuan-Ting Chen ${ }^{4}$, Cheng Liu' ${ }^{1}$, Jhi-Joung Wang ${ }^{2,4}$ \\ and Chin-Chen $\mathrm{Chu}^{4,5^{*}}$
}

\begin{abstract}
Background: The epidemiologic profile of ethnic Chinese patients with Dupuytren's disease is unknown. We therefore investigated the epidemiology of Dupuytren's disease using Taiwan's National Health Insurance Research Database.

Methods: Patients who filed claims for treatment for Dupuytren's disease between January 2000 and December 2011 were identified in the database. Age- and gender-specific incidences were estimated by dividing the incidence number by population data.

Results: We identified 1,078 patients with Dupuytren's disease (681 men, 397 women; male/female ratio: 1:1.72). The annual incidence rate ranged from $0.39-0.63 / 10^{5}$ for men and $0.14-0.44 / 10^{5}$ for women. A trend analysis revealed a rising trend in the annual incidence from 2001 to $2011(p=0.0199)$. The prevalence rate increased steadily from $0.46 / 10^{5}$ in 2000 to $4.52 / 10^{5}$ in 2011 ( $\left.p=0.0186\right)$. The mean age at onset was significantly higher in men than in women ( $60.7 \pm 18.4$ vs. $53.7 \pm 15.5$ years). Peak age at onset for men was 70-79 (28.1\%) and for women was 50-59 (33.5\%). Men > 60 years old had higher incidence rates than did women (incidence rate ratios: 2.0, 4.5, and 6.6 for those 60-69, $70-79$, and $\geq 80$, respectively). Hypertension (29.6\%), diabetes mellitus (21.9\%), hyperlipidemia (14.8\%), ischemic heart disease (10.5\%), and chronic obstructive pulmonary disease (8.0\%) were the most common comorbidities.

Conclusions: The incidence and prevalence of Dupuytren's disease and the male/female ratio were significantly lower in ethnic Chinese than in Western ethnic groups. Moreover, the age at onset was significantly lower in ethnic Chinese women. However, the incidences of three comorbidities (hypertension, diabetes mellitus, and hyperlipidemia) were similar to those in other ethnicities.
\end{abstract}

Keywords: Dupuytren's disease, Epidemiology, Ethnic, Chinese

\section{Background}

Dupuytren's disease (DD), also called Dupuytren's contracture or palmar fibromatosis, is a common and often irreversible and progressive fibroproliferative tissue contraction affecting the palmar fascia [1]. Its typical diagnostic features are the presence of a nodule and the subsequent formation of a contracture cord. The contracture usually begins in the palm and then progresses

\footnotetext{
* Correspondence: chinchen.chu@gmail.com

${ }^{4}$ Department of Anesthesiology, Chi Mei Medical Center, 901 Zhonghua Road, Yongkang District, Tainan 71004, Taiwan

${ }^{5}$ Department of Recreation and Health-Care Management, Chia-Nan University of Pharmacy and Science, Tainan, Taiwan

Full list of author information is available at the end of the article
}

distally, which results in finger flexion contracture. Nodules can present in both the palm and fingers. The ring finger is most often affected, and then, in order of frequency, the small finger, thumb, middle finger, and index finger [2]. DD is commonly bilateral, and it can become both a physically and a psychosocially disabling condition that significantly affects healthcare resources [3]. The etiology of DD is still not clear. Clinical studies show that it is strongly associated with genetic, geographic, and environmental factors [4]. DD has also been linked to many risk factors, including a history of smoking [5], alcohol consumption [6], frozen shoulder [7], epilepsy [8], diabetes mellitus [9], carpal tunnel syndrome [10], and hand injury [11]. 
Epidemiological data suggest that the highest prevalence of DD occurs in white northern Europeans. Tradition has it that the disease originated with the Vikings, who spread it throughout northern Europe and beyond as they traveled and intermarried [12]. DD is often called the "Viking" or "Nordic" disease. It is reported to be present in $46 \%$ of the population of Norway, 39\% of Scotland, 33\% of Iceland, and 32\% of Finland [13-15]. It is one of the most commonly inherited connective tissue disorders in Norwegians $>60$ years old [16]. Nevertheless, the disease does occur in nearly all populations [3,17-24]. The prevalence of Dupuytren's disease is $0.53 \%\left(533\right.$ per $\left.10^{5}\right)$ in Hispanics in the USA [23], 28\% in Australia [15], $3 \%$ in the USA, and $>4 \%$ in the male population in England [25]. DD is believed to be rare in Asians. In ethnic Chinese in particular, it is usually described as a sporadic finding, and the epidemiological reports on DD in Asians are limited to small case series reports $[19,26]$. In a population study in the USA, the prevalence of DD in Asians in one New York City hospital was $0.28 \%$ [23]. Given that the prevalence of DD varies greatly based on genetics, geography, and environment [8], the epidemiological data from other countries cannot be applied to ethnic Chinese. Therefore, using a nationwide database in Taiwan, we investigated the epidemiological profiles of DD in ethnic Chinese in Taiwan. Our findings should provide a better understanding of the reported epidemiological trends and comorbid factors of DD in ethnic Chinese.

\section{Methods}

\section{Database}

Population-based data were obtained from the reimbursement claims database of Taiwan's National Health Insurance (NHI). The NHI program began in Taiwan in 1995 and the NHI database contains annually updated information from 1997 to the present. All medical benefit claims for more than 99\% of Taiwan's 23 million legal residents (citizens and noncitizens) are included. The NHI Research Database (NHIRD) provides encrypted patient identification numbers, gender, date of birth, dates of admission and discharge, ICD-9-CM diagnosis and procedure codes (up to 5 each), details of prescriptions, and costs covered and paid for by the NHI. The NHI Bureau approved our use of these data, and Chi Mei Medical Center hospital institutional review board approval was waived for this study because patient information was encrypted.

\section{Patients and variables}

Patients with DD were identified either from ambulatory visits or from inpatient claims using the ICD-9-CM diagnosis code 728.6. We also recorded respiratory, cardiac, renal, cerebrovascular, and gastrointestinal comorbidities.
We counted these as comorbidities if the condition occurred either in inpatient claims or in 2 or more outpatient claims coded 12 months before and after the index medical care date for DD.

Outpatient claim files include an encrypted personal identification number, date of birth, date of service, relevant department, expenses, and the first 3 ICD-9 codes. Hospitalization discharge claims include an encrypted personal identification number, date of birth, length of stay, relevant department, expenses, and the first 5 ICD-9 codes. Multiple outpatient and hospitalization discharge claims with the same encrypted personal identification number were counted once so that only the incidence of the disease was counted. The prevalence was calculated by dividing the number of total cases for each year by the corresponding total population.

Average age- and gender-specific incidence rates were calculated by dividing the number of new cases in each age and gender group by the age- and gender-specific population, and then averaging these data from 2001 to 2011. Detailed age-specific population information for Taiwan used to calculate age-specific incidences in this study is from the Taiwan Ministry of the Interior, Executive Yuan (http://www.moi.gov.tw/stat/english/year.asp).

The communities in Taiwan were stratified into 7 urbanization categories according to the standards published by the Taiwanese National Health Research Institute (NHRI): code $1=$ most urbanized and code $7=$ least urbanized. These standards include the population density (people $/ \mathrm{km}^{2}$ ), the ratio of people with high educational levels (college or above), the ratio of people $\geq 65$ years old, the ratio of agricultural workers, and the number of physicians per 100,000 people [27].

\section{Statistical analysis}

SAS 9.3 for Windows (SAS Institute, Cary, NC, USA) was used for this study. Student's $t$ test was used to compare continuous variables (age differences between men and women). The incidence rate ratio was estimated using Poisson regression. For categorical variables, a two-tailed Fisher's Exact test was used for $<5$ cases (rheumatologic disease, pulmonary tuberculosis, valvular heart disease, and alcoholism) and Pearson's $x^{2}$ test for $>5$ cases (hypertension, diabetes mellitus, hyperlipidemia, ischemic heart disease, chronic obstructive pulmonary disease [COPD], stroke, cancer, hepatitis, and chronic renal failure level of urbanization, and hospital location). The Mantel-Haenszel extension of the $x^{2}$ test was used for trend analysis. Significance was set at $\mathrm{p}<0.05$.

\section{Results}

We identified 1078 cases of DD in the NHIRD (103 extant cases in 2000 and 975 new cases during 2001-2011; 681 men and 397 women) (Table 1). The annual incidence 
Table 1 Incidence and prevalence of Dupuytren's disease in Taiwan by gender

\begin{tabular}{|c|c|c|c|c|c|c|c|c|c|c|c|}
\hline \multirow[b]{2}{*}{ Year } & \multicolumn{2}{|c|}{ Total population $\times 10^{6}$} & \multicolumn{2}{|c|}{ New cases } & \multicolumn{2}{|c|}{ Total cases } & \multicolumn{2}{|c|}{ Incidence rate per $10^{5} /$ year } & \multicolumn{2}{|c|}{ Prevalence per $10^{5}$} & \multirow{2}{*}{$\begin{array}{l}\mathrm{M} / \mathrm{F} \text { ratio o } \\
\text { incidence }\end{array}$} \\
\hline & $\mathrm{M} / \mathrm{F}$ & Total & $\mathrm{M} / \mathrm{F}$ & Total & $\mathrm{M} / \mathrm{F}$ & Total & $\mathrm{M} / \mathrm{F}$ & Total & $\mathrm{M} / \mathrm{F}$ & Total & \\
\hline 2000 & $11.4 / 10.9$ & 22.3 & & & $67 / 36$ & 103 & & & $0.59 / 0.33$ & 0.46 & 1.78 \\
\hline 2001 & $11.4 / 11.0$ & 22.4 & $54 / 15$ & 69 & $121 / 51$ & 172 & $0.47 / 0.14$ & 0.31 & $1.06 / 0.46$ & 0.77 & 3.47 \\
\hline 2002 & 11.5/11.0 & 22.5 & $57 / 25$ & 82 & $178 / 76$ & 254 & $0.50 / 0.23$ & 0.36 & $1.55 / 0.69$ & 1.13 & 2.18 \\
\hline 2003 & 11.5/11.1 & 22.6 & $47 / 29$ & 76 & 229/105 & 329 & $0.41 / 0.26$ & 0.34 & $1.95 / 0.95$ & 1.46 & 1.56 \\
\hline 2004 & 11.5/11.1 & 22.7 & $45 / 35$ & 80 & $269 / 140$ & 409 & $0.39 / 0.32$ & 0.35 & $2.34 / 1.26$ & 1.86 & 1.24 \\
\hline 2005 & $11.6 / 11.2$ & 22.8 & $48 / 31$ & 79 & $314 / 171$ & 485 & $0.41 / 0.28$ & 0.35 & $2.71 / 1.53$ & 2.13 & 1.49 \\
\hline 2006 & 11.6/11.3 & 22.9 & $49 / 27$ & 76 & $363 / 198$ & 561 & $0.42 / 0.24$ & 0.33 & $3.13 / 1.75$ & 2.45 & 1.77 \\
\hline 2007 & $11.6 / 11.3$ & 23.0 & $61 / 23$ & 84 & $423 / 220$ & 643 & $0.53 / 0.20$ & 0.37 & $3.65 / 1.95$ & 2.80 & 2.58 \\
\hline 2008 & 11.6/11.4 & 23.0 & $56 / 44$ & 100 & $475 / 263$ & 738 & $0.48 / 0.39$ & 0.43 & $4.09 / 2.31$ & 3.21 & 1.25 \\
\hline 2009 & $11.6 / 11.5$ & 23.1 & $73 / 39$ & 112 & $545 / 300$ & 845 & $0.63 / 0.34$ & 0.48 & $4.70 / 2.61$ & 3.66 & 1.86 \\
\hline 2010 & $11.6 / 11.5$ & 23.2 & $67 / 42$ & 109 & $607 / 342$ & 949 & $0.58 / 0.37$ & 0.47 & $5.23 / 2.97$ & 4.09 & 1.58 \\
\hline 2011 & 11.6/11.6 & 23.2 & $57 / 51$ & 108 & $655 / 393$ & 1048 & $0.49 / 0.44$ & 0.47 & $5.65 / 3.39$ & 4.52 & 1.12 \\
\hline \multicolumn{3}{|c|}{ Total new cases } & $614 / 361$ & 975 & & & & & & & \\
\hline \multicolumn{3}{|c|}{ Total identified cases: } & $681 / 397$ & 1078 & & & & & & & 1.72 \\
\hline
\end{tabular}

$\mathrm{M} / \mathrm{F}$, male/female.

The data of total population are from the Directorate General of the Budget, Accounting, and Statistics, Executive Yuan, Taiwan. (http://www.moi.gov.tw/stat/ english/year.asp).

Trend analysis 2001-2011: for incidence rate $p=0.0199$ and for prevalence rate $p=0.0186$ (Mantel-Haenszel extension of the $x^{2}$ test).

rate ranged from $0.39-0.63 / 10^{5}$ for men and $0.14-0.44 / 10^{5}$ for women. A trend analysis revealed a rising trend in the annual incidence from 2001 to $2011(\mathrm{p}=0.0199)$. The incidence rate for men was always higher than for women (average M/F incidence ratio: 1.72 during 2001-2011). The prevalence rate increased steadily from $0.46 / 10^{5}$ in 2000 to $4.52 / 10^{5}$ in 2011 ( $\left.\mathrm{p}=0.0186\right)$. The prevalence in 2011 was $5.65 / 10^{5}$ for men and $3.39 / 10^{5}$ for women. Confidence intervals (CIs) are not reported because these are national population data, not a sample.

The mean age of patients with DD was significantly higher in men $(60.7 \pm 18.4$ years) than in women $(53.7 \pm 15.5)$ (Table 2). The incidence was lowest in the $<40$ age group and higher in the older age groups for both genders. The highest incidences were in 70- to 79year-old men (28.1\%) and 50- to 59-year-old women (33.5\%). The difference was significantly higher in 60- to 69-, 70- to 79-, and $\geq 80$-year-old men than in women in those age groups.

The most common comorbidities for these $1,078 \mathrm{pa}-$ tients were hypertension $(319 ; 29.6 \%)$, diabetes mellitus (236; $21.9 \%)$, hyperlipidemia (159; 14.8\%), ischemic heart disease $(113 ; 10.5 \%)$, and COPD $(86 ; 8.0 \%)$ (Table 3). Significantly more men had hypertension $(\mathrm{p}<0.001)$, ischemic heart disease $(\mathrm{p}=0.0167)$, and COPD $(\mathrm{p}<0.001)$ than did women. There were no significant differences between where the hospitals were or the degree of urbanization between men and women.

\section{Discussion}

This is not only the first population-based epidemiological study on DD in Taiwan, but it is also is the largest epidemiological study that has ever been conducted on DD in an Asian country, and one of very few that uses as its source one nation's entire stock of national health insurance claims data. Because of the low incidence, it is difficult and impractical to field community studies for an epidemiological approach. The NHIRD, however, is a prodigious resource for studying the epidemiology of rare diseases like DD. We found that both the incidence and prevalence rates of DD are much lower for ethnic Chinese in Taiwan than for Europeans $[14,28,29]$ and US Americans $[24,30]$. However, the annual incidence rate of DD in Taiwan increased during the study period, especially for women. We also found that the most common comorbidities in ethnic Chinese DD patients were hypertension, diabetes mellitus, hyperlipidemia, ischemic heart disease, and COPD.

Other studies' estimated prevalence rates of DD ranged from $0.2 \%$ [31] to $56 \%$ [32]; the large range is attributable to variations in age, population groups, and methods of data collection. Most of the epidemiological data were obtained by sampling specific populations $[14,21,24,33]$ or by retrospectively reviewing charts [23,34]. For instance, one US study [24] estimated the prevalence rate of DD using an online survey from an Internet-based research panel representative of the US population, and 
Table 2 Age-specific average incidence of Dupuytren's disease in Taiwan during 2000-2011

\begin{tabular}{|c|c|c|c|c|c|c|c|c|c|}
\hline \multirow[b]{3}{*}{ Age group (years) } & \multirow{2}{*}{\multicolumn{2}{|c|}{ Cases $n$ (\%) }} & \multirow{3}{*}{$\begin{array}{l}\text { Total } \\
(n=1078)\end{array}$} & \multirow[b]{3}{*}{$M / F$} & \multicolumn{4}{|c|}{ Average incidence } & \multirow[b]{3}{*}{$p$} \\
\hline & & & & & \multicolumn{3}{|c|}{ per $10^{5} /$ year } & \multirow{2}{*}{$\begin{array}{l}\mathrm{M} / \mathrm{F} \text { incidence } \\
\text { Rate ratio }(95 \% \mathrm{Cl})\end{array}$} & \\
\hline & $M(n=681)$ & $F(n=397)$ & & & $M$ & $\mathrm{~F}$ & Total & & \\
\hline$<40$ & $83(12.2 \%)$ & $60(15.1 \%)$ & $143(13.3 \%)$ & 1.38 & 0.10 & 0.08 & 0.09 & $1.3(0.9-1.8)$ & 0.1069 \\
\hline $40-49$ & $75(11.0 \%)$ & $74(18.6 \%)$ & 149 (13.8\%) & 1.01 & 0.34 & 0.34 & 0.34 & $1.0(0.7-1.4)$ & 0.9964 \\
\hline $50-59$ & $118(17.3 \%)$ & $133(33.5 \%)$ & $251(23.3 \%)$ & 0.89 & 0.73 & 0.81 & 0.77 & $0.9(0.7-1.2)$ & 0.3992 \\
\hline $60-69$ & $149(21.9 \%)$ & 79 (19.9\%) & $228(21.2 \%)$ & 1.89 & 1.64 & 0.81 & 1.21 & $2.0(1.5-2.6)$ & $<0.0001$ \\
\hline $70-79$ & $191(28.1 \%)$ & 41 (10.3\%) & $232(21.5 \%)$ & 4.65 & 2.94 & 0.65 & 1.81 & $4.5(3.3-6.2)$ & $<0.0001$ \\
\hline$\geq 80$ & $65(9.5 \%)$ & 10 (12.2\%) & $75(2.5 \%)$ & 6.50 & 2.37 & 0.36 & 1.36 & $6.6(3.7-11.7)$ & $<0.0001$ \\
\hline Age $($ mean $\pm S D)$ & $60.7 \pm 18.4$ & $53.7 \pm 15.5$ & & & & & & & $<0.0001$ \\
\hline
\end{tabular}

$M$, male; $F$, female.

Data are $n(\%)$ unless otherwise indicated.

Table 3 Gender-specific comorbidities, urbanization, and hospital level for 1078 patients with Dupuytren's disease in Taiwan

\begin{tabular}{|c|c|c|c|c|}
\hline Variables & Total = $1078(100 \%)$ & Male $=681(100 \%)$ & Female = $397(100 \%)$ & ${ }^{*} p$ \\
\hline \multicolumn{5}{|l|}{ Comorbidities ( $n(\%))$} \\
\hline Hypertension & $319(29.6)$ & $231(33.9)$ & $88(22.2)$ & $<0.0001^{\$}$ \\
\hline Diabetes mellitus & $236(21.9)$ & $163(23.9)$ & $73(18.4)$ & $0.0336^{\$}$ \\
\hline Hyperlipidemia & 159 (14.8) & $95(14.0)$ & $64(16.1)$ & $0.3323^{\$}$ \\
\hline Ischemic heart disease & $113(10.5)$ & $83(12.2)$ & $30(7.6)$ & $0.0167^{\$}$ \\
\hline COPD & $86(8.0)$ & $74(10.9)$ & $12(3.0)$ & $<0.0001^{\$}$ \\
\hline Stroke & $54(5.0)$ & $40(5.9)$ & $14(3.5)$ & $0.0884^{\$}$ \\
\hline Cancers & $37(3.4)$ & $26(3.8)$ & $11(2.8)$ & $0.3624^{\$}$ \\
\hline Hepatitis (B or C) & $17(1.6)$ & $11(1.6)$ & $6(1.5)$ & $0.8949^{\$}$ \\
\hline CKD & $21(2.0)$ & $11(1.6)$ & $10(2.5)$ & $0.3005^{\$}$ \\
\hline Rheumatic disease & $14(1.3)$ & $3(0.4)$ & $11(2.8)$ & $0.0017 \&$ \\
\hline Pulmonary tuberculosis & $8(0.7)$ & $5(0.7)$ & $3(0.8)$ & $1.0000 \&$ \\
\hline Valvular heart disease & $7(0.7)$ & $5(0.7)$ & $2(0.5)$ & $0.6496 \&$ \\
\hline Alcoholism & $1(0.1)$ & $1(0.2)$ & $0(0.0)$ & $1.0000 \&$ \\
\hline Urbanization & & & & $0.0980^{\$}$ \\
\hline 1 (highest) & $275(25.5)$ & $179(26.3)$ & $96(24.2)$ & \\
\hline 2 & $567(52.6)$ & $366(53.7)$ & $201(50.6)$ & \\
\hline 3 & $38(3.5)$ & $17(2.5)$ & $21(5.3)$ & \\
\hline 4 & $171(15.9)$ & $101(14.8)$ & $70(17.6)$ & \\
\hline$\geq 5$ & $27(2.5)$ & $18(2.6)$ & $9(2.3)$ & \\
\hline Hospital location & & & & $0.4407^{\$}$ \\
\hline 1. North & $579(53.7)$ & $375(55.1)$ & $204(51.4)$ & \\
\hline 2. Central & $158(14.7)$ & $95(14.0)$ & $63(15.9)$ & \\
\hline 3. South & $316(29.3)$ & $193(28.34)$ & $123(31.0)$ & \\
\hline 4. East & $25(2.3)$ & $18(2.6)$ & $7(1.8)$ & \\
\hline
\end{tabular}

COPD: chronic obstructive pulmonary disease. CKD, chronic kidney disease.

Urbanization: level 1 indicating most urbanized and level 7 indicating least urbanized. Criteria for calculating urbanization include population density (people/km ${ }^{2}$ ), ratio of people with high educational levels (college or above), the ratio of people $\geq 65$ years old, the ratio of agricultural workers, and the number of physicians per 100,000 people.

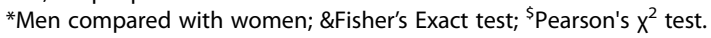


one Belgian study [14] estimated it from a random visit by a physician to a market. Our estimate, however, is based not on a sampling, but on data from Taiwan's NHIRD, into which data are entered without a selection bias. No similar information is available in the published literature in Taiwan or in any other Asian country. Because the diagnosis of DD was already recorded using ICD-9 codes, and because each diagnosis was made by a physician rather than being based on the patient's memory on a health history questionnaire, a misclassification bias is unlikely. Because patients with only mild symptoms might not seek medical help, and therefore will not be entered in the database, the incidence and prevalence may be underestimated. However, DD is a proliferative and progressive disease, and most people who have it will ultimately need medical attention. Therefore, if the observation period is long enough, the underestimation will become smaller. Furthermore, because more than $98 \%$ of Taiwan's population is ethnic Chinese [35], our data can represent the epidemiological features of DD in ethnic Chinese.

The two main foci of epidemiological studies are incidence rate and prevalence rate. The former is defined as the number of new cases of a disease over a specific time-period and the latter as the current number of cases of disease at a single point in time. Most previous epidemiological studies of DD that have quoted incidence rates were in fact referring to prevalence rate [15]. In the present study, we identified new cases every year from the NHIRD. The average annual incidence rate of DD in Taiwan during 2000-2011 was only $0.39 / 10^{5}$ (men $0.48 / 10^{5}$; women $0.29 / 10^{5}$ ), which was much lower than that of a UK study [29] (502,493 men; annual incidence: $34.3 / 10^{5}$ men), and of a US population-based study [24] (annual incidence: estimated at 30.0/10 adults). We found that DD in Taiwan was much less prevalent than in Western countries $[14,21,22,33]$. Ethnic studies $[14,17,21]$ show that DD is highly prevalent in Scandinavians. A US veterans-hospital-based study [30] reported that the prevalence of DD is highest in Whites and then Hispanic Whites, Blacks, and Asians.

The epidemiological reports on DD in Asia are only case series or else are limited to special groups. A Taiwanese study [19] reported 41 cases of DD in Taiwan during 1970-1988. Because it was case series from a single hospital, neither an incidence rate nor a prevalence rate could be reported. In addition, a Japanese crosssectional study [36] of 1,154 patients reported prevalence rates of $19.7 \%$ for men and $9 \%$ for women. Because all the patients were more than 60 years old and lived in nursing homes, they did not represent a general population.

In the present study, we found a trend of rising incidence and prevalence rates from 2001 to 2011. We hypothesize that the trend is a reflection of the aging population because the prevalence and severity of DD increases with age [37]. Moreover, the incidence of DD increases with comorbidities like diabetes mellitus [9,31], hyperlipidemia [38,39], and hypertension [23,40], all of which are highly prevalent in the elderly [41-44]. Furthermore, the universal coverage and low copayment of Taiwan's NHI system has increased the affordability of healthcare here, which increases the diagnostic rate for DD. In addition, increased medical knowledge from the Internet might also contribute to the higher contemporary rate of medical consultation [45].

The average age at the onset of DD is about 60 years old, and the incidence rises thereafter [13,37]. Similarly, in our study, the onset of DD age-dependently increased for men, and the incidence rate peaked at $2.94 / 10^{5}$ person-years at age 70-79 and dropped a little to $2.37 / 10^{5}$ person-years for men over 80 . For women $<40$ years old, however, the incidence rate jumped from $0.08 / 10^{5}$ to $0.81 / 10^{5}$ person-years for those $50-69$ years old, and fell by $20 \%$ to $0.65 / 10^{5}$ person-years for those $70-79$ and then by $55 \%$ to $0.36 / 10^{5}$ person-years for $\geq 80$. These rates are different from those reported $[46,47]$ for other ethnicities, in which the incidence continuously increased with age in women.

Another unique epidemiology profile for DD in ethnic Chinese is that there are no gender differences in incidence rates for patients $<60$, but for those $\geq 60$, the incidence rates increased more dramatically for men than for women. The male:female incidence rate ratio increases from 2.0 to 6.6 for those $60-69$ and $\geq 80$ years old. This is quite different from reports on other ethnicities in which the gender difference in the incidence rate diminishes with increasing age; specifically; the male:female incidence rate ratio approaches $1: 1$ for people $\geq 80$ $[17,25,46,47]$. Additional studies are necessary to determine the underlying mechanisms.

Generally, DD is much less common in women than in men, with reported overall male:female incidence rate ratios ranging from $1.7: 1$ to $9.5: 1[37,46,47]$. Similar to what has been reported in the literature, our results show that both the incidence and prevalence rates are higher for men than for women in Taiwan. The male:female incidence and prevalence rate ratios, however, are 1.72 and 1.55 , which are lower than those for Europeans and Australians [37,46], but close to that for US Americans [47]. Additionally, a US study [46] reported that women were older (mean age: 62.4 years) at their first operation (62.4 years) than were men (59.8 years). Other studies $[14,21]$ also report that age at the onset of DD is about 10 years lower in men than in women. However, in the present study, the mean age at onset was about 7 years lower in women (53.72 years) than in men (60.69 years). This, however, might be attributable to genetic and environmental differences between 
populations. Moreover, the present study is an epidemiological profile report of DD in Taiwanese; thus, from our results, no direct evidence can be drawn determine the underlying mechanism for the early onset of DD in Taiwanese women.

A number of epidemiologic factors have been associated with the development of DD: e.g., diabetes mellitus, hyperlipidemia, hypertension, epilepsy, smoking, and alcoholism [13,15,37,48]. We found that hypertension, diabetes mellitus, and hyperlipidemia were the most common comorbidities both in men and in women. All of these diseases may impair microvascular circulation and cause localized ischemia, which increases free radicals and inflammatory cytokines [37], and concomitantly alters gene expressions of growth factors, adhesion molecules, and extracellular matrix components that, in turn, trigger the proliferation of DD tissue [49].

Our study has some limitations. First, our cohort was identified by ICD-9 codes coded by physicians. Patients with only mild symptoms might not seek medical care and thus were not included in our database. Therefore, the calculation of incidence and prevalence rates based on the NHIRD might underestimate the true rates. Second, data on several environmental factors believed to contribute to DD development, including alcohol intake, smoking, manual labor, or exposure to vibrations [37], were not available in the NHIRD. Only one man among our identified 1,078 patients had been diagnosed with alcoholism; this is undoubtedly an underestimated prevalence rate of habitual alcohol drinking for Taiwan. Third, although the administrative claims data allowed us to identify patients diagnosed with DD, they did not contain information about the severity of the disease. Fourth, there were no data about blood biochemistry, pathology reports, or finger function; thus, it was not possible to determine whether the disease was progressing or in remission. Fifth, although $98 \%$ of Taiwanese residents are ethnic Chinese, there are residents of other ethnicities, most of whom are aboriginal Austronesian Taiwanese [35]. Patients' ethnicities were not recorded in the NHIRD; therefore, we did not know the distribution of DD in ethnic Chinese and aborigines. However, the highest population density of Taiwanese aborigines is in eastern Taiwan, and DD is lowest in that area. Sixth, although the $\mathrm{NHI}$ regularly investigates the quality of the ICD-9 coding in the claims database to ensure that diagnoses in particular are accurate, we still cannot exclude the possibility that some might be incorrect because of mistakes by the medical coders and physicians responsible for entering the codes. These limitations may compromise our findings.

\section{Conclusions}

The incidence and prevalence rates of DD in ethnic Chinese in Taiwan were much lower than those reported for other ethnic groups in the rest of the world. Moreover, DD in Taiwan has an earlier onset in ethnic Chinese women and a lower M:F incidence rate ratio. However, diabetes mellitus, hyperlipidemia, and hypertension, the most common comorbidities of DD in ethnic Chinese, were similar to those in other ethnic groups. Additional studies are needed in order to determine, for example, whether the underlying mechanisms are genetic, environmental, or socioeconomic factors, or some combination of these.

\section{Competing interests}

The authors declare that they have no competing interests.

\section{Authors' contributions}

CCY reviewed the literature reviews, designed the study, and drafted the manuscript. $\mathrm{CHH}$ participated in the design of the study and did the statistical analysis. KFH, KTC and CL participated in the literature reviews and data interpretation. JJW involved in revising the manuscript and provided administrative technical support. CCC conceived the study, and participated in its design, in the coordination and interpretation of the data, and in the revision of the manuscript. All authors read and approved the final manuscript.

\section{Acknowledgements}

This study is based on data from the National Health Insurance Research Database provided by the Taiwan Bureau of National Health Insurance, Department of Health, and managed by the National Health Research Institutes. The interpretation and conclusions contained herein do not represent those of the Bureau of National Health Insurance, the Department of Health, or the National Health Research Institutes.

We thank Bill Franke for English editing.

\section{Author details}

'Division of Plastic Surgery, Department of Surgery, Chi-Mei Medical Center, Yong-Kang, Tainan, Taiwan. ${ }^{2}$ Department of Medical Research, Chi-Mei Medical Center, Tainan, Taiwan. ${ }^{3}$ Department of Hospital and Health Care Administration, Chia-Nan University of Pharmacy and Science, Tainan, Taiwan. ${ }^{4}$ Department of Anesthesiology, Chi Mei Medical Center, 901 Zhonghua Road, Yongkang District, Tainan 71004, Taiwan. ${ }^{5}$ Department of Recreation and Health-Care Management, Chia-Nan University of Pharmacy and Science, Tainan, Taiwan.

Received: 18 August 2014 Accepted: 22 January 2015

Published online: 10 February 2015

\section{References}

1. Tomasek JJ, Vaughan MB, Haaksma CJ. Cellular structure and biology of Dupuytren's disease. Hand Clin. 1999;15(1):21-34.

2. Lanting R, Nooraee N, Werker PM, van den Heuvel ER. Patterns of dupuytren disease in fingers: studying correlations with a multivariate ordinal logit model. Plast Reconstr Surg. 2014;134(3):483-90.

3. Maravic M, Landais P. Dupuytren's disease in France-1831 to 2001-from description to economic burden. J Hand Surg. 2005;30(5):484-7.

4. Michou L, Lermusiaux JL, Teyssedou JP, Bardin T, Beaudreuil J, Petit-Teixeira E. Genetics of Dupuytren's disease. Joint Bone Spine. 2012;79(1):7-12.

5. Burge $P$, Hoy G, Regan P, Milne R. Smoking, alcohol and the risk of Dupuytren's contracture. J Bone Joint Surg. 1997;79(2):206-10.

6. Noble J, Arafa M, Royle SG, McGeorge G, Crank S. The association between alcohol, hepatic pathology and Dupuytren's disease. J Hand Surg Br. 1992;17(1):71-4.

7. Smith SP, Devaraj VS, Bunker TD. The association between frozen shoulder and Dupuytren's disease. J Shoulder Elbow Surg. 2001;10(2):149-51.

8. Mikkelsen OA. Dupuytren's disease-initial symptoms, age of onset and spontaneous course. Hand. 1977;9(1):11-5.

9. Arkkila PE, Kantola IM, Viikari JS. Dupuytren's disease: association with chronic diabetic complications. J Rheumatol. 1997:24(1):153-9.

10. Bonnici AV, Birjandi F, Spencer JD, Fox SP, Berry AC. Chromosomal abnormalities in Dupuytren's contracture and carpal tunnel syndrome. J Hand Surg. 1992;17(3):349-55. 
11. Kelly SA, Burke FD, Elliot D. Injury to the distal radius as a trigger to the onset of Dupuytren's disease. J Hand Surg. 1992;17(2):225-9.

12. Flatt AE. The Vikings and Baron Dupuytren's disease. Proceedings. 2001;14(4):378-84.

13. Shaw Jr RB, Chong AK, Zhang A, Hentz VR, Chang J. Dupuytren's disease: history, diagnosis, and treatment. Plast Reconstr Surg. 2007;120(3):44e-54e.

14. Degreef I, De Smet L. A high prevalence of Dupuytren's disease in Flanders. Acta Orthop Belg. 2010;76(3):316-20.

15. Hindocha S, McGrouther DA, Bayat A. Epidemiological evaluation of Dupuytren's disease incidence and prevalence rates in relation to etiology. Hand (N Y). 2009;4(3):256-69.

16. Burge P. Genetics of Dupuytren's disease. Hand Clin. 1999;15(1):63-71.

17. Mikkelsen OA. The prevalence of Dupuytren's disease in Norway. a study in a representative population sample of the municipality of Haugesund. Acta Chir Scand. 1972;138(7):695-700.

18. Makhlouf MV, Cabbabe EB, Shively RE. Dupuytren's disease in blacks. Ann Plast Surg. 1987;19(4):334-6.

19. Liu Y, Chen WY. Dupuytren's disease among the Chinese in Taiwan. J Hand Surg. 1991;16(5):779-86.

20. Gonzalez MH, Sobeski J, Grindel S, Chunprapaph B, Weinzweig N. Dupuytren's disease in African-Americans. J Hand Surg. 1998;23(3):306-7.

21. Gudmundsson KG, Arngrimsson R, Sigfusson N, Bjornsson A, Jonsson T. Epidemiology of Dupuytren's disease: clinical, serological, and social assessment. The Reykjavik Study. J Clin Epidemiol. 2000;53(3):291-6.

22. Finsen $V$, Dalen $H$, Nesheim J. The prevalence of Dupuytren's disease among 2 different ethnic groups in northern Norway. J Hand Surg. 2002;27(1):115-7.

23. Weinstein AL, Haddock NT, Sharma S. Dupuytren's disease in the Hispanic population: a 10-year retrospective review. Plast Reconstr Surg. 2011;128(6):1251-6.

24. Dibenedetti DB, Nguyen D, Zografos L, Ziemiecki R, Zhou X. Prevalence, incidence, and treatments of Dupuytren's disease in the United States: results from a population-based study. Hand (N Y). 2011;6(2):149-58.

25. Early PF. Population studies in dupuytren's contracture. J Bone Joint Surg Br. 1962;44-B(3):602-13.

26. Slattery D. Review: Dupuytren's disease in Asia and the migration theory of Dupuytren's disease. ANZ J Surg. 2010;80(7-8):495-9.

27. Liu CY, Hung YT, Chuang YL, Chen YJ, Weng SW, Liu JS, et al. Incorporating development stratification of Taiwan townships into sampling design of large scale health interview survey. J Health Manag. 2006;4(1):1-22.

28. Jurisic D, Kovic I, Lulic I, Stanec Z, Kapovic M, Uravic M. Dupuytren's disease characteristics in Primorsko-goranska County, Croatia. Coll Antropol. 2008;32(4):1209-13.

29. Khan AA, Rider OJ, Jayadev CU, Heras-Palou C, Giele H, Goldacre M. The role of manual occupation in the aetiology of Dupuytren's disease in men in England and Wales. J Hand Surg. 2004;29(1):12-4.

30. Srivastava S. Racial distribution of Dupuytren's disease in Department of Veteran's Affairs patients. Plast Reconstr Surg. 2001;107(7):1912.

31. Geoghegan JM, Forbes J, Clark DI, Smith C, Hubbard R. Dupuytren's disease risk factors. J Hand Surg. 2004;29(5):423-6.

32. Critchley EM, Vakil SD, Hayward HW, Owen VM. Dupuytren's disease in epilepsy: result of prolonged administration of anticonvulsants. J Neurol Neurosurg Psychiatry. 1976;39(5):498-503.

33. Zerajic D, Finsen V. Dupuytren's disease in Bosnia and Herzegovina. An epidemiological study. BMC Musculoskelet Disord. 2004;5:10.

34. Loos B, Puschkin V, Horch RE. 50 years experience with Dupuytren's contracture in the Erlangen University Hospital-a retrospective analysis of 2919 operated hands from 1956 to 2006. BMC Musculoskelet Disord. 2007;8:60.

35. Tseng $\mathrm{CH}$. The ethnicity of Hakka is associated with a higher risk of hypertension than Fukienese in Taiwanese type 2 diabetic patients. J Hum Hypertens. 2008;22(5):370-2.

36. Egawa T, Senrui H, Horiki A. Dupuytren's disease in Japanese. Singapore: Longman; 1990.

37. Shih B, Bayat A. Scientific understanding and clinical management of Dupuytren disease. Nat Rev Rheumatol. 2010;6(12):715-26.

38. Macaulay D, Ivanova J, Birnbaum H, Sorg R, Skodny P. Direct and indirect costs associated with Dupuytren's contracture. J Med Econ. 2012;15(4):664-71.

39. Sanderson PL, Morris MA, Stanley JK, Fahmy NR. Lipids and Dupuytren's disease. J Bone Joint Surg. 1992;74(6):923-7.
40. Larkin JG, Frier BM. Limited joint mobility and Dupuytren's contracture in diabetic, hypertensive, and normal populations. Br Med J. 1986;292(6534):1494.

41. Lin CC, Li Cl, Hsiao CY, Liu CS, Yang SY, Lee CC, et al. Time trend analysis of the prevalence and incidence of diagnosed type 2 diabetes among adults in Taiwan from 2000 to 2007: a population-based study. BMC Public Health. 2013;13:318.

42. Menke A, Rust KF, Fradkin J, Cheng YJ, Cowie CC. Associations between trends in race/ethnicity, aging, and body mass index with diabetes prevalence in the United States: a series of cross-sectional studies. Ann Intern Med. 2014;161(5):328-35.

43. Arai H, Yamamoto A, Matsuzawa Y, Saito Y, Yamada N, Oikawa S, et al. Serum lipid survey and its recent trend in the general Japanese population in 2000. J Atheroscler Thromb. 2005:12(2):98-106.

44. Liu L, Ikeda K, Chen M, Yin W, Mizushima S, Miki T, et al. Obesity, emerging risk in China: trend of increasing prevalence of obesity and its association with hypertension and hypercholesterolaemia among the Chinese. Clin Exp Pharmacol Physiol. 2004;31 Suppl 2:S8-10.

45. Sheng $X$, Simpson PM. Seniors, health information, and the Internet: motivation, ability, and Internet knowledge. Cyberpsychol Behav Soc Netw. 2013;16(10):740-6.

46. Wilbrand S, Ekbom A, Gerdin B. The sex ratio and rate of reoperation for Dupuytren's contracture in men and women. J Hand Surg. 1999;24(4):456-9.

47. Anthony SG, Lozano-Calderon SA, Simmons BP, Jupiter JB. Gender ratio of Dupuytren's disease in the modern U.S. population. Hand (N Y). 2008;3(2):87-90

48. Khashan M, Smitham PJ, Khan WS, Goddard NJ. Dupuytren's Disease: Review of the Current Literature. Open Orthop J. 2011;5 Suppl 2:283-8.

49. Rehman S, Goodacre R, Day PJ, Bayat A, Westerhoff HV. Dupuytren's: a systems biology disease. Arthritis Res Ther. 2011;13(5):238.

\section{Submit your next manuscript to BioMed Central and take full advantage of:}

- Convenient online submission

- Thorough peer review

- No space constraints or color figure charges

- Immediate publication on acceptance

- Inclusion in PubMed, CAS, Scopus and Google Scholar

- Research which is freely available for redistribution 